\title{
Fundamental Properties and Durability of Concrete with Gasification Molten Slag as Fine Aggregate
}

\author{
Takafumi Watanabe, Hiromi Fujiwara, Masanori Maruoka and Koji Satori
}

\author{
Graduate School of Regional Development and Creativity, Utsunomiya University, \\ 7-1-2 Yoto, Utsunomiya City, Tochigi Prefecture, Japan, mc196264@cc.utsunomiya-u.ac.jp
}

\begin{abstract}
The proportion of electricity generated by coal-fired thermal power plants has been rising in Japan as a result of the nuclear plant accident caused by the Great East Japan Earthquake of 2011. Coal-fired electricity generation has a large environment impact, so the commercial application of integrated coal gasification combined cycle (IGCC) has been promoted. IGCC is an efficient generating method combining a steam turbine and a gas turbine. However, IGCC plants generate coal gasification molten slag (CGMS) and it is necessary to establish effective utilization methods for this slag for further promotion of IGCC technology. In this paper, the fresh properties, hardened properties and durability of concrete containing CGMS as fine aggregate are investigated. The results show that, in comparison with concrete using conventional fine aggregate, the air content introduced by an air-entraining agent is lower and bleeding is increased when CGMS is used as a fine aggregate. As for the hardened properties, compressive strength is slightly lower, while freeze-thaw resistance is significantly reduced. In additional tests, it is found possible to improve freeze-thaw resistance by increasing the air content.
\end{abstract}

Keywords: Coal Gasification Molten Slag, Fine Aggregate, Freeze-Thaw Resistance, Integrated Coal Gasification Combined Cycle (IGCC).

\section{Introduction}

With environmental concerns restricting the extraction of natural aggregate, Japan's concrete industry is finding it difficult to secure supplies and is pursuing research to develop substitute aggregates. On the other hand, following the Great East Japan Earthquake and tsunami of 2011, the composition of Japan's electricity supply has tilted toward thermal power generation in place of the nuclear power that was predominant. Currently coal-fired power generation accounts for approximately $32.3 \%$ of all electricity generated in Japan. Conventional coal-fired power stations emit tremendous quantities of $\mathrm{CO}_{2}$, so technology to reduce $\mathrm{CO}_{2}$ emissions is needed. For this reason, the use of the highly efficient Integrated Gasification Combined Cycle (IGCC) has been promoted. With IGCC technology, impurities from coal that has been heated in a gasification furnace are melted and discharged as coal gasification molten slag (CGMS). CGMS is an amorphous material formed by rapid granulation in water. Establishing a method for effective use of this CGMS is essential to expansion of IGCC utilization. It is thought that using CGMS as concrete aggregate could make a major contribution to society. However, no standards have yet been established for such use of CGMS. This study investigates the potential for use of CGMS as a concrete aggregate. The fundamental properties of concrete incorporating CGMS are estimated and problems that must be resolved are isolated in order to provide data for the establishment of standards for the use of CGMS aggregate. 


\section{Characteristics of CGMS Fine Aggregate}

The characteristics of the CGMS and crushed sand used as fine aggregates in this study were measured and compared. Figure 1 shows electron microscope pictures of the CGMS fine aggregate (symbol: $\mathrm{Sg}$ ) and crushed sand (symbol: $\mathrm{Sc}$ ) used in this study.

Table 1 gives the chemical composition of CGMS. The main components are silicon dioxide, aluminum oxide, calcium oxide and iron trioxide, which account for more than $90 \%$ by weight, with trace amounts of other minerals. These are all oxides of naturally existing elements.

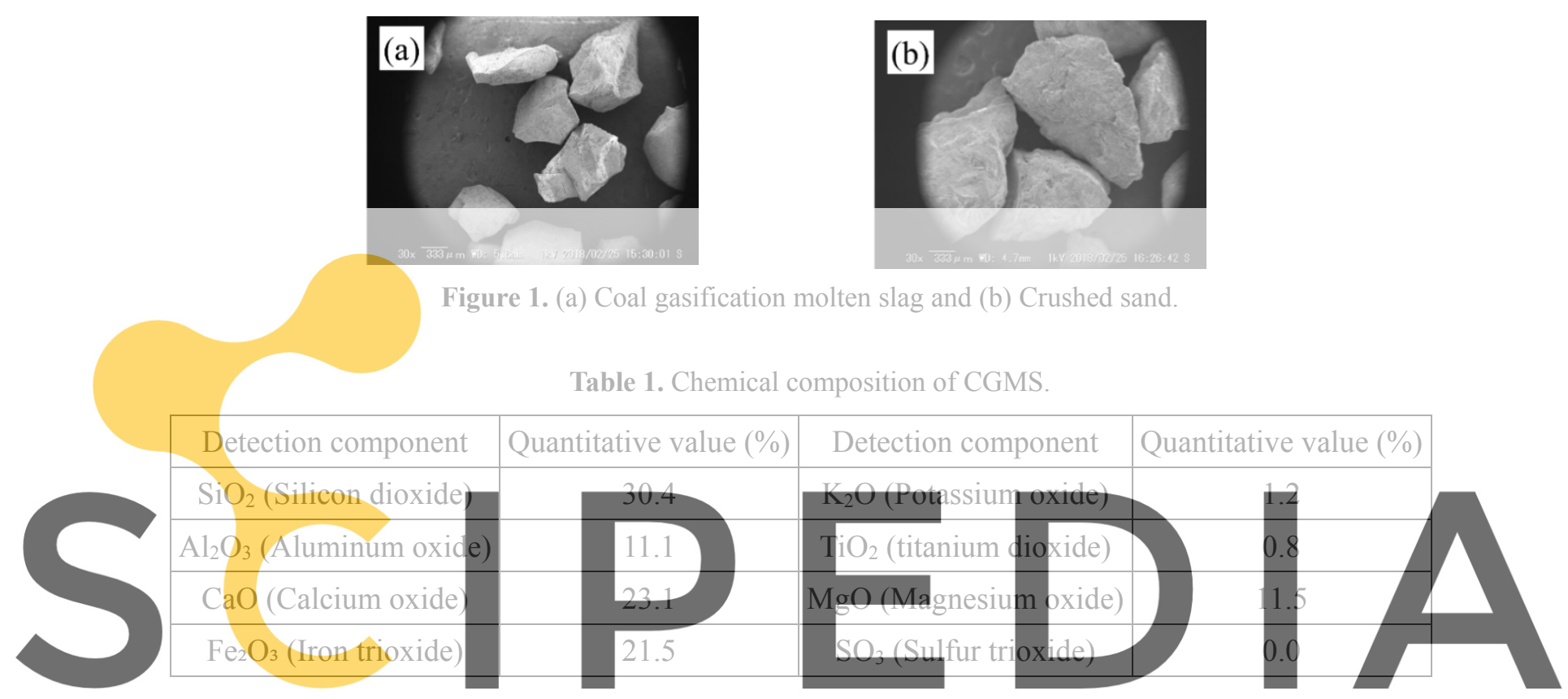

\subsection{Test Items}

Register for free at https / www.scipedia, com to download the version without the watermark under $75 \mu \mathrm{m}$ sieve, and solid volume percentage for shape determination were measured according to ISO, ASTMI and EN.

In order to estimate strength and elastic deformation for use as aggregate, an aggregate strength indicator test was developed and used to characterize the CGMS and crushed sand aggregates. A steel container with an inner diameter of $33 \mathrm{~mm}$ and a height of $88 \mathrm{~mm}$ was used for this test. Figure 2 outlines this aggregate strength indicator test. The test is carried out as follows.

Under fully dried condition, aggregate with particles in the range $1.2-2.5 \mathrm{~mm}$ is separated by screening. Then $60 \mathrm{~g}$ of the separated particles are placed in the steel container and the upper surface is smoothed using the finger. A round steel loading bar is then inserted and a precision universal testing machine used to apply a compressive load $\mathrm{P}(\mathrm{kN})$ while at the same time measuring the displacement $\mathrm{d}(\mathrm{mm})$ using a laser displacement gauge. Loading continues up to a maximum of $90 \mathrm{kN}$. A load-displacement curve is drawn from the measurements and the gradient of the proportional section of the curve is calculated as the aggregate strength index using Equation (1) below. 


$$
I(\mathrm{kN} / \mathrm{mm})=P(\mathrm{kN}) / d(\mathrm{~mm})
$$

where: $I$ is the aggregate strength index value;

$P$ is the compressive load; and

$d$ is the displacement.

After the test, the particles are screened through a $0.30 \mathrm{~mm}$ sieve and then a $0.15 \mathrm{~mm}$ sieve, and the 0.30 crushing value $(\%)$ and 0.15 crushing value $(\%)$ are calculated from the quantity passing each sieve. These crushing values are calculated using the following equations (2) and (3).

$$
\begin{aligned}
& 0.30 \text { crushing value }=\mathrm{B}(\mathrm{g}) / \mathrm{A}(\mathrm{g}) \times 100(\%) \\
& 0.30 \text { crushing value }=\mathrm{C}(\mathrm{g}) / \mathrm{A}(\mathrm{g}) \times 100(\%)
\end{aligned}
$$

Where: $\mathrm{A}$ is the weight of crushed aggregate;

$\mathrm{B}$ is the weight of aggregate passing the $0.30 \mathrm{~mm}$ sieve; and

$\mathrm{C}$ is the weight of aggregate passing the $0.15 \mathrm{~mm}$ sieve.
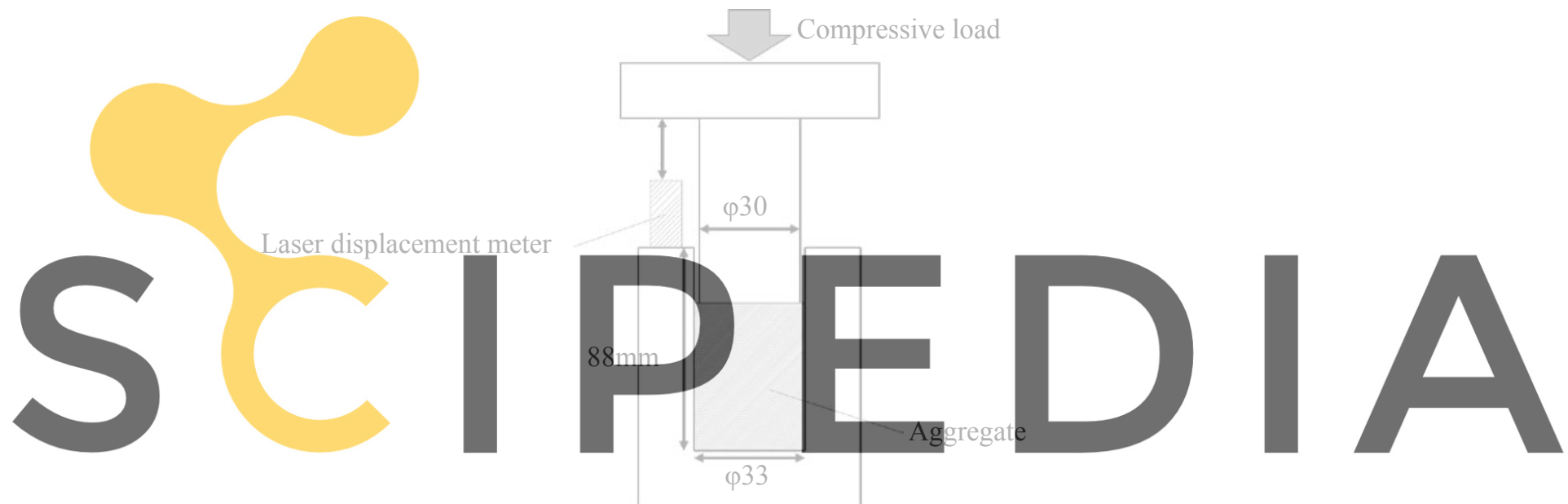

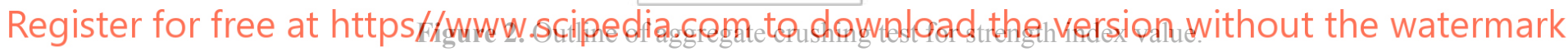

\subsection{Test Results}

Table 2 shows the standard test results for the CGMS fine aggregate and crushed sand. Figure 3 shows the particle size distributions of the two fine aggregates as determined by sifting. The CGMS fine aggregate used in this study had a larger density of $3.08 \mathrm{~g} / \mathrm{cm}^{3}$ in saturated surfacedry condition compared with crushed sand. Its water absorption rate is $0.70 \%$, which is lower than that of crushed sand.

From these results, it is inferred that CGMS fine aggregate has a smooth surface and it is possible to reduce the restrained water volume on the surface of the aggregate. This leads to the expectation that the unit volume of water needed for a given slump can be reduced as compared to crushed sand. As the solid content and the solid volume percentage for shape determination are almost the same as the crushed sand values, it is thought that CGMS fine aggregate has appropriate particle shapes and sizes. From these data, improved fluidity can be expected for fresh concrete made with CGMS fine aggregate.

Figure 4 shows the relationships between compressive load and displacement in the aggregate strength indicator test. The resulting strength index values are shown in Table 3. These results show that CGMS fine aggregate has a higher strength index value than crushed 
sand, resulting in greater resistance to deformation under external force. Moreover, the crushing values indicate that CGMS fine aggregate is more brittle than crushed sand.

Table 2. Characteristics of CGMS fine aggregate and crushed sand.

\begin{tabular}{|c|c|c|c|c|}
\hline \multicolumn{2}{|c|}{} & \multirow{2}{*}{ Test method } & \multicolumn{2}{|c|}{ Test value } \\
\cline { 5 - 6 } & & $\mathrm{Sg}$ & $\mathrm{Sc}$ \\
\hline Density in saturated surface-dry condition & $\mathrm{g} / \mathrm{cm}^{3}$ & & 3.08 & 2.64 \\
\hline Absolute dry density & $\mathrm{g} / \mathrm{cm}^{3}$ & ISO 7033:1987 & 3.06 & 2.60 \\
\cline { 5 - 6 } & & & 0.70 & 1.33 \\
\hline Water absorption rate & $\mathrm{kg} / \mathrm{L}$ & & \\
\hline Bulk density & $\%$ & & 2.05 & 1.75 \\
\hline Solid content & $\%$ & ASTM C117 & 4.7 & 2.7 \\
\hline Content of materials finer than $75 \mu \mathrm{m}$ sieve & $\%$ & EN 933-3 & 57.1 & 56.7 \\
\hline Solid volume percentage for shape determination & $\%$ & & 66.9 & 67.3 \\
\hline Fineness modulus & & ISO 6274:1982 & 2.50 & 2.73 \\
\hline
\end{tabular}

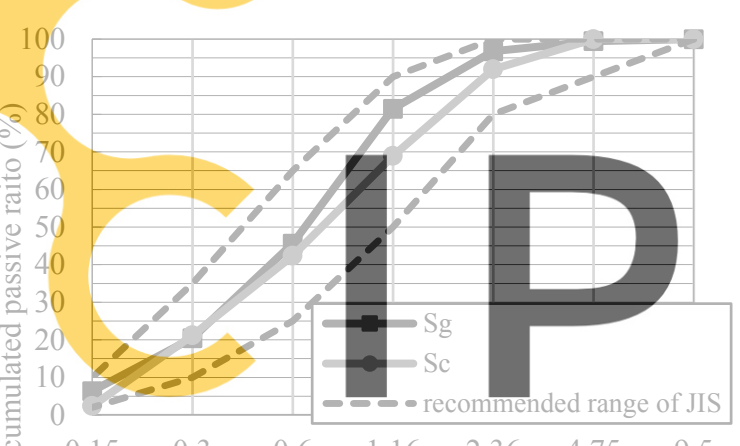

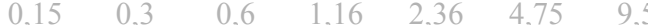

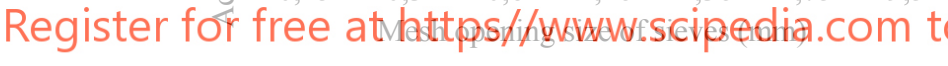

Figure 3. Particle size distribution of fine aggregates.

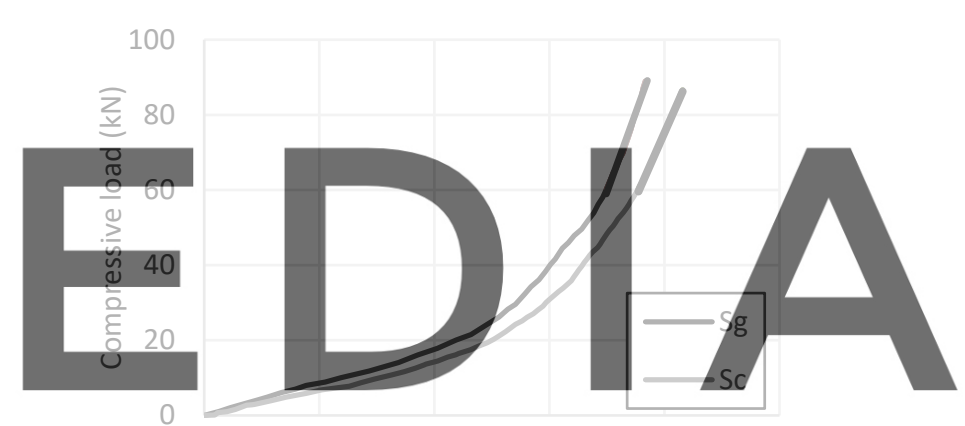

$5 \quad 10 \quad 15 \quad 20 \quad 25$ version without the watermark Displacement $(\mathrm{mm})$

Figure 4. Relationship between compressive load and displacement.

Table 3. Aggregate strength index value and aggregate crushing test results.

\begin{tabular}{|c|c|c|}
\hline Aggregate strength index value: I & Sg & Sc \\
\hline Crushing value $0.30(\%)$ & 27.6 & 13.9 \\
\hline Crushing value $0.15(\%)$ & 21.7 & 13.0 \\
\hline
\end{tabular}

\section{Fundamental Properties of Concrete Using CGMS as Fine Aggregate}

\subsection{Materials}

Ordinary portland cement (symbol: $\mathrm{C}$, density: $3.16 \mathrm{~g} / \mathrm{cm}^{3}$ ) was used as binder. Crushed sand $(\mathrm{Sc})$ and CGMS fine aggregate $(\mathrm{Sg})$ were used as fine aggregates. Crushed stone (symbol: $\mathrm{G}$; density in saturated surface-dry condition: $2.61 \mathrm{~g} / \mathrm{cm}^{3}$ ) was used as the coarse aggregate.

Additionally, a high-performance water reducing admixture (symbol: SP), an air-entraining admixture (symbol: AE) and a deformer (symbol: DF) were included as admixtures. 


\subsection{Mixture Proportions}

Table 4 shows the mixture proportions of the concrete used to cast specimens. The water-cement ratio was fixed at $50 \%$. Sand fine aggregate was replaced by CGMS at volume ratios of $0 \%$, $50 \%$ and $100 \%$; the replacement ratio is expressed as $\mathrm{Sg} / \mathrm{S}$. The target values of fresh properties were $12.0 \pm 1.5(\mathrm{~cm})$ for slump and $4.5 \% \pm 1.5 \%$ for air content. The rate of high-performance water reducing admixture addition was also fixed to $0.75 \%$ by mass, after an initial study in which the target values of fresh properties were obtained at this addition rate with $\mathrm{Sg} / \mathrm{S}=100 \%$. In order to obtain the target values at $\mathrm{Sg} / \mathrm{S}=0 \%$ and $\mathrm{Sg} / \mathrm{S}=50 \%$, the unit volume of water was adjusted so as to carry out evaluations based on the unit volume of water that satisfied the target values, while keeping the SP addition rate constant.

Table 4. Mixture proportioning of concrete for fresh property testing.

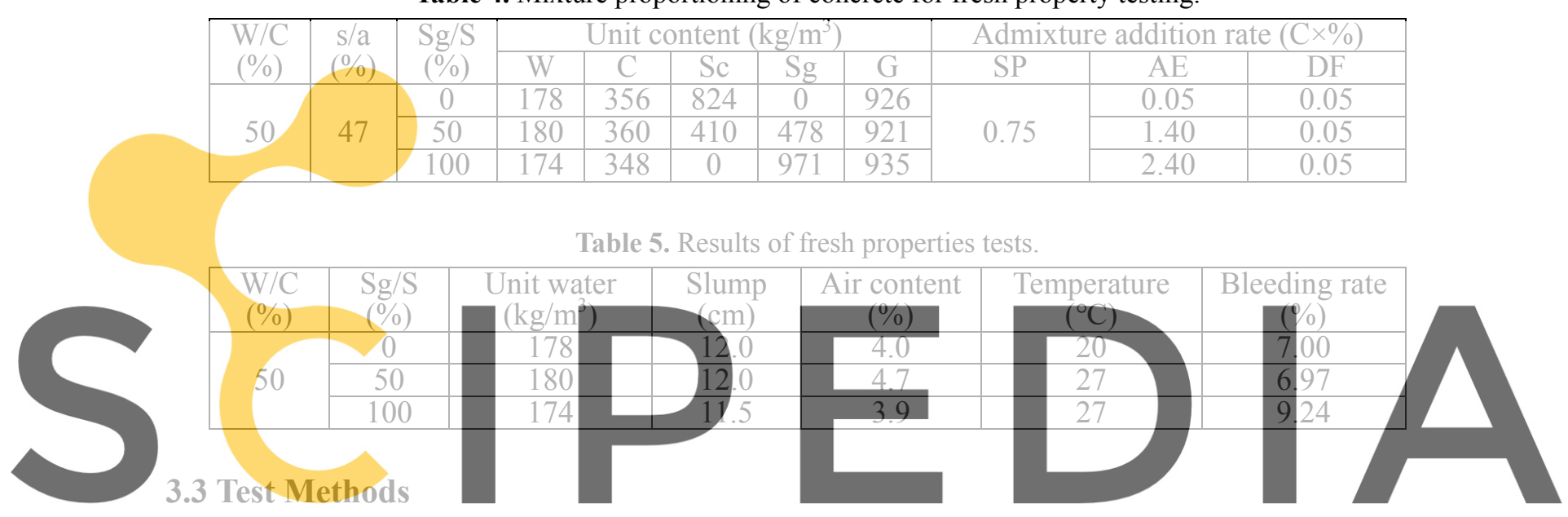

The fresh properties measured were concrete slump, air content, concrete temperature, and

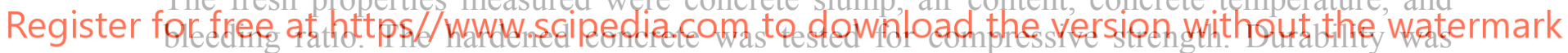
investigated by carrying out freeze-thaw tests, drying shrinkage tests and accelerated carbonation tests. These were all in accordance with ISO and ASTM.

\subsection{Test Results}

Table 5 shows the results of the fresh properties tests. The bleeding rate was found to increase at higher $\mathrm{Sg} / \mathrm{S}$ ratios. With $\mathrm{Sg} / \mathrm{S}=100 \%$, the unit water volume was lower but the bleeding rate increased. This is thought to be because the CGMS fine aggregate has a smooth surface and low water absorption rate, so there is a greater surplus of water when the mix includes more CGMS. And also, it is considered that water content increased. Then the same slump value could be obtained at lower unit water amount.

Figure 5 shows the results of the compressive strength tests. Concrete with CGMS fine aggregate has a slightly lower strength compared with concrete without it. This is considered to be because CGMS itself is not as strong as crushed sand, noting that the crushing values of CGMS fine aggregate are larger. Further, with the increased bleeding, it is also considered that voids in the interfaces with coarse aggregate particles increased, resulting in weaker interface bonding between coarse aggregate and cement paste.

Figure 6 shows the results of the freeze-thaw tests. Concrete including CGMS fine aggregate 
showed very poor frost resistance. It is thought that this is because of the weaker interface bonding between paste and coarse aggregate particles, resulting from the high bleed rate. The expansion pressure of freezing water in the voids causes this reduced resistance. There is a need for studies aimed at improving the freeze-thaw resistance of concretes containing CGMS fine aggregate.

Figure 7 shows the results of the drying shrinkage tests. With higher $\mathrm{Sg} / \mathrm{S}$, drying shrinkage strain decreased. The reason for this is considered to be that, since the aggregate strength index of CGMS fine aggregate is larger, its deformation resistance is larger. With a higher $\mathrm{Sg} / \mathrm{S}$ ratio, the unit water content decreased. As a result, drying shrinkage was reduced.

Figure 8 shows the results of the accelerated carbonation test. With a higher $\mathrm{Sg} / \mathrm{S}$ ratio, the carbonation rate increased. More bleeding occurred at higher $\mathrm{Sg} / \mathrm{S}$, so a coarser microstructure formed in the concrete, allowing $\mathrm{CO} 2$ to enter the concrete more easily.

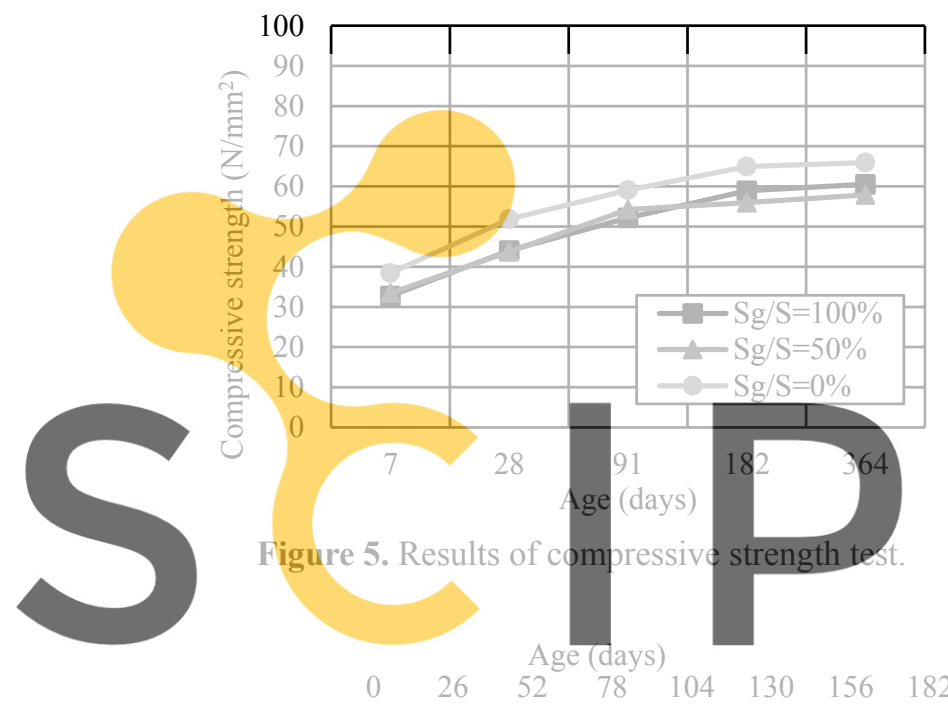

Register for free at https//www.scipedjia.com to

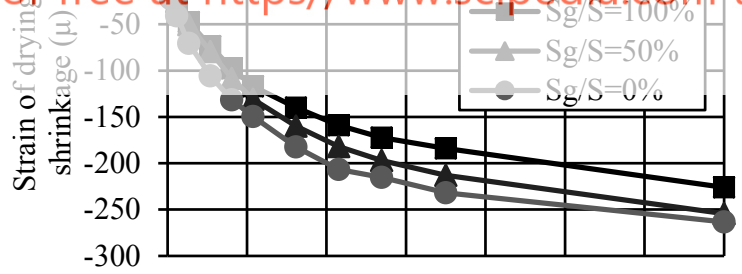

Figure 7. Results of drying shrinkage test.

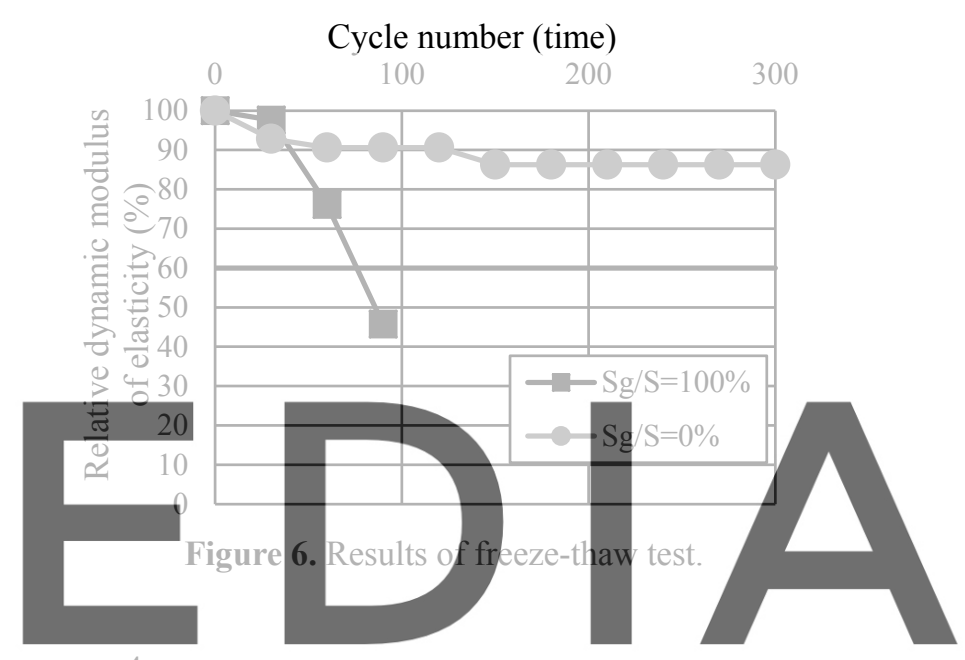

$\overline{\mathrm{A}}^{4} \mathrm{~m}$ load the version without the watermark

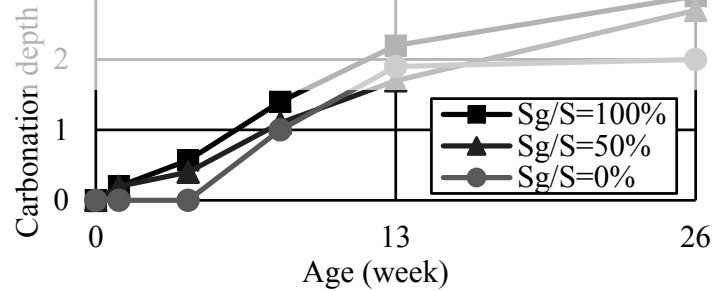

Figure 8. Results of accelerated carbonation test.

\section{Experiment to Improve the Frost Resistance of Concrete Including CGMS Fine Aggregate}

The results of the freeze-thaw test show that the resistance of concrete made with CGMS fine aggregate is significantly reduced. A possible method of improving freeze-thaw resistance by increasing the air content was examined.

Table 6 shows the mix proportions of the concrete used in this experiment and the results of the fresh properties tests. 
The water-cement ratio was fixed at 50\%. Sand fine aggregate was replaced by CGMS at a volume ratio $(\mathrm{Sg} / \mathrm{S})$ of $100 \%$. The target values of fresh properties were $12.0 \pm 1.5(\mathrm{~cm})$ for slump and the three values of air content: $4.5 \pm 1.5 \%, 6.0 \pm 0.5 \%$ and $7.5 \pm 0.5 \%$. As an additional test, the air-void spacing factor was measured by the linear-traverse method. This test was implemented in accordance with ASTM C 457-98.

Table 6. Mixture proportioning of concrete for freeze-thaw testing and results of fresh property tests.

\begin{tabular}{|c|c|c|c|c|c|c|c|c|c|c|c|}
\hline \multirow{2}{*}{ Symbol } & \multirow{2}{*}{$\begin{array}{l}\mathrm{W} / \mathrm{C} \\
(\%)\end{array}$} & \multicolumn{4}{|c|}{$\begin{array}{l}\text { Unit content } \\
\left(\mathrm{kg} / \mathrm{m}^{3}\right)\end{array}$} & \multicolumn{3}{|c|}{$\begin{array}{l}\text { Admixture addition } \\
\text { rate }(\mathrm{C} \times \%)\end{array}$} & \multirow{2}{*}{$\begin{array}{c}\text { Air } \\
\text { content } \\
(\%)\end{array}$} & \multirow{2}{*}{$\begin{array}{l}\text { Slump } \\
(\mathrm{cm})\end{array}$} & \multirow{2}{*}{$\begin{array}{c}\text { Temperature } \\
\left({ }^{\circ} \mathrm{C}\right)\end{array}$} \\
\hline & & $\mathrm{W}$ & $\mathrm{C}$ & $\mathrm{Sg}$ & $\mathrm{G}$ & SP & $\mathrm{AE}$ & $\mathrm{DF}$ & & & \\
\hline Sg-4.5 & \multirow{3}{*}{50} & 174 & 348 & 971 & 935 & \multirow{3}{*}{0.75} & 2.40 & 0.05 & 3.9 & 11.5 & 27 \\
\hline Sg-6.0 & & 171 & 342 & 978 & 942 & & 1.40 & 0.05 & 5.5 & 10.5 & 27 \\
\hline Sg-7.5 & & 169 & 338 & 983 & 947 & & 2.20 & 0.05 & 7.7 & 13.0 & 28 \\
\hline
\end{tabular}

\subsection{Test Results}

Figure 9 shows the results of the freeze-thaw test and Figure 10 shows the relationship between air-void spacing factor and durability factor. As can be seen in these results, freeze-thaw resistance was greatly improved by increasing the air content.

The experiment demonstrated that the entrainment of air in concrete containing CGMS fine aggregate is low during mixing. In order to obtain the target air content, it was necessary to add a large amount of AE admixture. These results indicate that CGMS contains a large amount of non-combustion carbon and this will require further stud

The air-void spacing

$7.5 \%$ than when it was

the amount of air increased. $\mathrm{A}$.

air content.

These results demonstrate that the freeze-thaw resistance

aggregate can be improved, but further study is needed.

Register for free at https//www.scipedia.com to download the version without the watermark Cycle number (time)

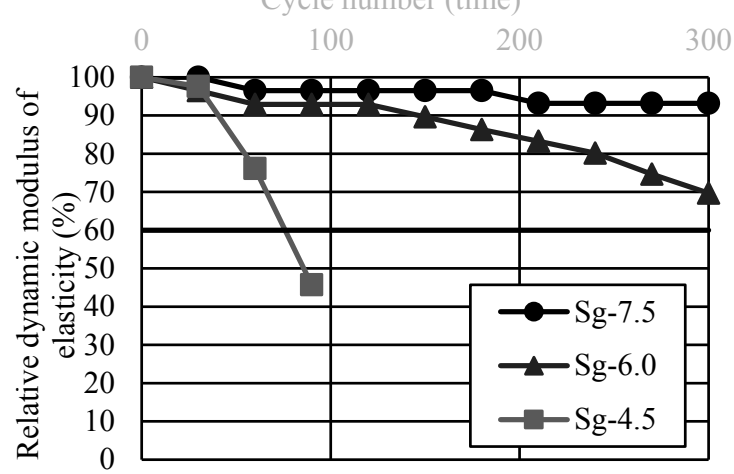

Figure 9. Results of freeze-thaw test.

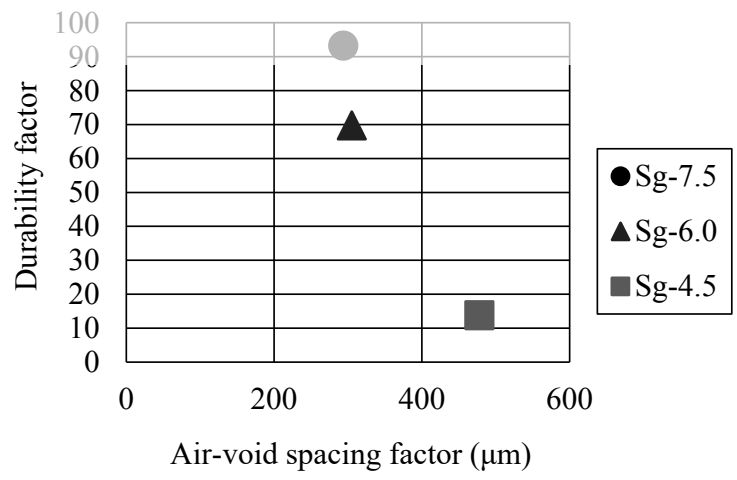

Figure 10. Relationship between air-void spacing factor and durability factor. 


\section{Conclusions}

Experiments to determine the basic properties of concrete containing CGMS as fine aggregate showed that fluidity improved while compressive strength decreased slightly. In other results, drying shrinkage strain was reduced while carbonation resistance decreased.

In terms of durability, tests of freeze-thaw resistance were not very good. However, freeze-thaw resistance was shown to be improved by increasing the air content of the fresh concrete.

\section{Acknowledgements}

In this research project, Coal Energy Center of the General Foundation provided us with slag, adjusted its granularity and offered opportunities for testing. The research was entrusted to us by New Energy and Industrial Technology Development Organization (NEDO). The authors thank these organizations for their cooperation.

\section{References}

Ministry of Economy, Trade and Industry. (2019). Agency for Natural Resources and Energy: Outline of the Energy White Paper; https://www.enecho.meti.go.jp/about/whitepaper/2019pdf/whitepaper2019pdf_2_1.pdf

Yuto Yamanaka, Hiromi Fujiwara, Masanori Maruoka and Ryosuke Otsuka (2018). "Experimental Study on Properties of Mortar Containing Molten Slag from Integrated Coal Gasification Combined Cycle as Fine Aggregate", Proceeding of 2nd International Workshop on Durability and Sustainable of Concrete Structures, USB

Ryotaro Kobayashi, Hiromi Fujiwara, Masanori Maruoka and Yuto Yamanaka (2019). "Experimental study on

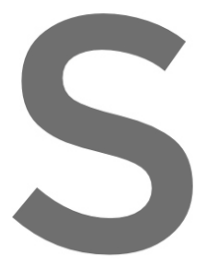
properties of concrete Proceedings of Internat 271
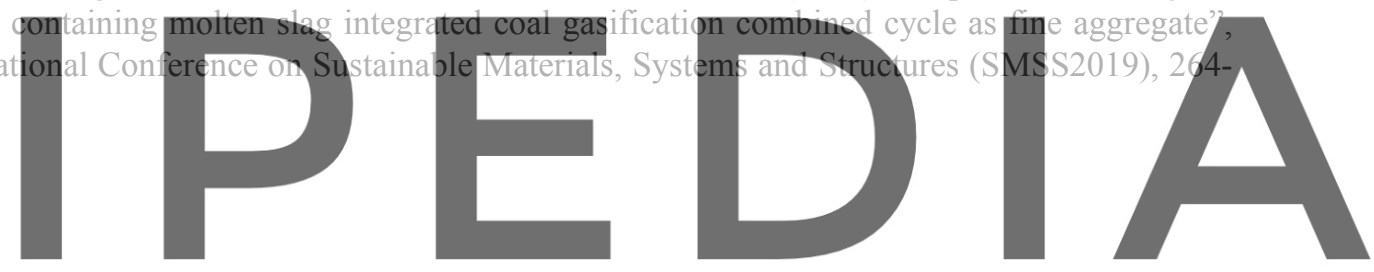

Register for free at https//www.scipedia.com to download the version without the watermark 